\title{
Cui bono? PEG feeding
}

\author{
Authors: Heather Parr ${ }^{A}$ and David S Sanders ${ }^{B}$
}

Percutaneous endoscopic gastrostomy (PEG) provides longterm nutritional support to those unable to tolerate intake orally. The benefits of a PEG depend on the indication and the individual, and are considered when it has the potential to improve mortality, nutritional status or quality of life. Often, family members and healthcare professionals have to act on behalf of the patient. It is difficult for their personal values and emotions to not be a factor when deciding if to proceed with a PEG. This may result in unnecessary PEG placement. For certain indications (dementia for example), there is limited evidence of any benefits a PEG may give and may actually cause harm. Guidance to improve patient selection and increase education for healthcare professionals is essential in achieving the best outcome for the patient.

KEYWORDS: PEG, ethics, nutrition

DOI: 10.7861/clinmed.2020-0759

\section{Introduction}

There is an increasing number of percutaneous endoscopic gastrostomies (PEGs) performed since the procedure was first established back in 1979. ${ }^{1}$ It is now estimated that over 17,000 PEGs are performed annually in the UK. ${ }^{2}$ There are numerous reasons why a patient may be referred for a PEG, however in 2004, the report of the National Confidential Enquiry into Patient Outcome and Death (NCEPOD) found that one in five PEG procedures were done unnecessarily; either because they were futile or not indicated. ${ }^{3}$ Since then, new guidance has been developed to try and improve patient selection. Up to threequarters of patients in hospital may not have capacity to consent when referred for a gastrostomy. ${ }^{4}$ The patient, therefore, often relies on family and healthcare professionals to make decisions on their behalf.

\section{Indications}

A PEG provides long-term nutritional support in those who have a functioning gastrointestinal tract but are unable to tolerate intake orally. To date, the indications for PEG tend to come under four main headings: cerebrovascular disease, neurodegenerative

Authors: ${ }^{A}$ gastroenterology registrar, Royal Hallamshire Hospital, Sheffield, UK; B professor of gastroenterology, Royal Hallamshire Hospital, Sheffield, UK diseases, oropharyngeal malignancy and cerebral contusions. ${ }^{5}$ With ongoing advancements in medicine, there continues to be an increasing number of conditions that may benefit from a PEG. For example, percutaneous endoscopic jejunostomies (PEJ) can be used to improve medication effectiveness in patients with Parkinson's disease by delivering medications directly into the small bowel. ${ }^{6}$

\section{Benefits}

The benefits of a PEG depend on the indication and the individual. A PEG should be considered when it has the potential to improve mortality, nutritional status and/or quality of life, as well as aiding earlier discharge from hospital. ${ }^{2}$

When considering different sub-groups of patients in whom a PEG is inserted, early enteral feeding after a stroke has been shown to increase survival. ${ }^{7}$ There is some evidence that patients with motor neuron disease (MND) may have increased survival and nutritional benefit; however, there has not been any clear demonstration of improvement in quality of life. ${ }^{8}$ A PEG tube may provide an advantage for nutrition maintenance compared to a nasogastric (NG) tube for those undergoing treatment for head and neck cancer. ${ }^{9,10}$ Irrespective of the indications, there is a paucity of high-quality evidence or randomised controlled studies. However, such levels of evidence may be hard to obtain when considering such an emotive intervention.

The impact a PEG may have on a patient's quality of life is likely to vary depending on the pathology for which it was indicated. ${ }^{11}$ For some, spending less time on meals and more stable nutrition provides improved wellbeing. It is likely to have a more positive impact on body image when compared to an NG tube. ${ }^{9,10}$ Due to the fact that not all facilities have the trained staff necessary to safely use NG tubes, a PEG may aid discharge, preventing an unnecessary or prolonged stay in hospital and allow rehabilitation and specialist physiotherapy to be provided early.

\section{Complications}

Complications for PEG include aspiration, infection and bleeding, as well as later issues such as tube dysfunction and displacement, buried bumper and, in some cases, obstruction and fistula. ${ }^{12}$ Although classed as a relatively safe procedure, these complications are somewhat common. One hospital recently found approximately $25 \%$ of their patients experienced both acute and chronic complications. ${ }^{13}$

More recently, studies have started to look at the longer holistic outcomes of gastrostomy insertion and assess quality of life. PEG feeding may improve quality of life for some, but not always. 
A recent UK study did not show a significant improvement in quality of life for the patient or the carer. ${ }^{14}$ A gastrostomy often has a significant impact on the activities of daily living and it is rare for a patient to not have experienced some problems with a PEG, including pain, anxiety and social isolation. ${ }^{14,15}$ As with all invasive procedures, the patient and relatives need to weigh up the potential benefits versus the risks associated with the procedure and it may not be worthwhile if any benefits are likely to be short lived. The NCEPOD report found a death rate of $43 \%$ within 1 week after PEG and $63 \%$ at 30 days. $^{3}$

\section{Dementia patients}

There is no evidence to date that PEG feeding increases survival, nutritional status or aspiration risk in patients with dementia; world-wide guidelines say to usually avoid PEGs in this group. ${ }^{16}$ In one study, there had been up to $54 \%$ mortality at 1 month and $90 \%$ at 1 year in this group of patients. ${ }^{17}$ PEG-fed nursing home residents may have a higher risk of developing pressure ulcers, hypothesised due to the increased need to restrain these patients or the potential increase in diarrhoea from the osmolarity of the feed. ${ }^{18}$ Despite this, the preferred method of feeding in dementia patients is still artificial feeding, usually via a PEG. ${ }^{2,19}$

\section{For whose benefit?}

\section{Family}

Deciding whether to proceed with a PEG on behalf of their relative can be highly emotive for family members. Feeding is thought to be a basic requirement and some feel that denying their relative a PEG is letting them 'starve'. A common belief, even among healthcare professionals, is that a PEG will automatically be of benefit. ${ }^{16,20}$ It becomes difficult to adjust this belief, especially when a PEG has already been suggested by a healthcare professional. Decisions will have a time limit and it is unlikely a decision can be made without an emotional involvement. It has previously been found that a third of relatives, when interviewed, later regretted or had reservations about their decision to proceed with a PEG. ${ }^{21}$

\section{Healthcare professionals}

Views among healthcare professionals when it comes to a PEG vary greatly. ${ }^{20}$ Decisions are influenced by culture, religion, education and likely pressure from a patient's family members. ${ }^{22}$ Formal training in healthcare professionals has been found to be as low as $15 \% .{ }^{20}$ Around a quarter of patients referred for PEG do not undergo the procedure and mortality in this group was found to be approximately $75 \%$ at 1 year. ${ }^{23}$ Junior medical staff and nurses were more likely to recommend PEG feeding in elderly advanced dementia patients than dietitians, gastroenterologists and geriatricians. ${ }^{20}$

\section{The patient}

For patients who have proceeded with PEG insertion despite being advised against it, there has been no survival benefit found. ${ }^{24}$. When survival can be increased, it could be at the expense of prolonging life but with a poor outcome. ${ }^{7}$ When patients are unable to consent, those involved with the decision may feel they are helping the patient but may not want the same decision made for themselves. A previous study on healthcare professionals found that $82 \%$ of them would not want to be kept alive if they were in a vegetative state and $28 \%$ if minimally conscious. ${ }^{25}$

\section{New implications}

The recommendations after the NCEPODs findings in 2004 were that all patients for PEG should be reviewed by a multidisciplinary team (MDT). Patients need to be referred on a specific referral form, have their risk factors assessed and be seen by one of the enteral feeding team prior to their procedure., ${ }^{3,12}$ This review helps improve patient selection by aiming to address common misconceptions held by patients and family members, and ensure all involved are working towards the same goal. ${ }^{24}$

Other strategies put in place to improve selection include scoring systems, such as the Sheffield gastrostomy score, which estimates 30-day mortality post-PEG. This can help guide the clinician's assessment and provide some quantitative evidence to give to the patient and their family. ${ }^{26}$ Some centres have adopted a "cooling off period' where PEGs are not performed until at least a week later. This gives time to reconsider and for any acute deterioration to be taken into account. ${ }^{27}$ Finally, more centres are now providing valuable after-care, such as community PEG nurses and outpatient clinics to support the patient and carer with any problems that may arise. ${ }^{2}$

\section{Conclusion}

The decision to proceed with a PEG involves more than just the patient. Family members and all members of their medical team play an important role in deciding the best interests of the patient. There is limited evidence of the benefits of a PEG in many indications and, at times, a PEG may actually cause harm. It is important that all members of the healthcare team are trained to recognise which indication and individual is appropriate for a PEG referral. The most important part of the MDT process will arguably be the time spent pre-procedure with the patient and family to advise and manage expectations. Knowing that feeding is emotive, should we as clinicians pose the question to ourselves 'primum non nocere' [first do no harm] when considering this intervention?

\section{References}

1 Gauderer MWL, Ponsky JL, Izant RJ. Gastrostomy without laparotomy: A percutaneous endoscopic technique. J Pediatr Surg 1980;15:872-5.

2 Kurien M, Westaby D, Romaya C, Sanders DS. National survey evaluating service provision for percutaneous endoscopic gastrostomy within the UK. Scand J Gastroenterol 2011;46:1519-24.

3 National Confidential Enquiry into Patient Outcome and Death. Scoping our practice. NCEPOD, 2004.

4 Rahman M, Evans KE, Arif N, Gorard DA. Mental incapacity in hospitalised patients undergoing percutaneous endoscopic gastrostomy insertion. Clin Nutr 2012;31:224-9.

5 Kurien M, Williams J, Sanders DS. Malnutrition in healthcare settings and the role of gastrostomy feeding. Proc Nutr Soc 2017;76:352-60.

6 Specialised Commissioning Team, NHS England. Clinical Commissioning Policy: Levodopa-Carbidopa Intestinal Gel (LCIG). NHS, 2015. www.england.nhs.uk/commissioning/wp-content/ uploads/sites/12/2015/07/d04-p-e.pdf

7 Dennis MS, Lewis SC, Warlow C, FOOD Trial Collaboration. Effect of timing and method of enteral tube feeding for dysphagic stroke patients (FOOD): a multicentre randomised controlled trial. Lancet 2005:365:764-72 
8 Katzberg HD, Benatar M. Enteral tube feeding for amyotrophic lateral sclerosis/motor neuron disease. Cochrane Database Syst Rev 2011:2011:CD004030.

9 Corry J, Poon W, McPhee N et al. Prospective study of percutaneous endoscopic gastrostomy tubes versus nasogastric tubes for enteral feeding in patients with head and neck cancer undergoing (chemo)radiation. Head Neck 2009;31:867-76.

10 Gomes Jr CA, Andriolo RB, Bennett C et al. Percutaneous endoscopic gastrostomy versus nasogastric tube feeding for adults with swallowing disturbances. Cochrane Database Syst Rev 2015;2015:CD008096.

11 Wanden-Berghe C, Nolasco A, Sanz-Valero J, Planas M, Cuerda C. Health-related quality of life in patients with home nutritional support. J Hum Nutr Diet 2009;22:219-25.

12 Westaby D, Young A, O'Toole P, Smith G, Sanders DS. The provision of a percutaneously placed enteral tube feeding service. Gut 2010;59: 1592-605.

13 Pih GY, Na HK, Ahn JY et al. Risk factors for complications and mortality of percutaneous endoscopic gastrostomy insertion. BMC Gastroenterol 2018;18:101.

14 Kurien M, Andrews RE, Tattersall R et al. Gastrostomies preserve but do not increase quality of life for patients and caregivers. Clin Gastroenterol Hepatol 2017;15:1047-54.

15 Green SM, Townsend K, Jarrett N, Westoby C, Fader M. People with enteral tubes and their carers' views of living with a tube and managing associated problems: A qualitative interview study. J Clin Nurs 2019;28:3710-20.

16 Sampson E, Candy B, Jones L. Enteral tube feeding for older people with advanced dementia. Cochrane Database Syst Rev 2009; 2009:CD007209.

17 Sanders DS, Carter MJ, D'Silva ] et al. Survival analysis in percutaneous endoscopic gastrostomy feeding: a worse outcome in patients with dementia. Am J Gastroenterol 2000;95:1472-5.

18 Teno JM, Gozalo P, Mitchell SL et al. Feeding tubes and the prevention or healing of pressure ulcers. Arch Intern Med 2012; 172:697-701.

19 Newman RD, Ray R, Woodward L, Glass B. Factors contributing to the preferred method of feeding in end-stage dementia: a scoping review. Dysphagia 2020;35:616-29.
20 Adu-Tei S, Penny HA, El-Fekhi M, Ruse C, Sanders DS. Healthcare professionals' attitudes towards PEG tube feeding in advanced dementia: time to engage with a wide clinical audience? Minerva Gastroenterol Dietol 2019;65:246-8.

21 Rosendaal V, Guido MA, Verhoef MJ, Mace SR, Douglas KT. Decision-making and outcomes for percutaneous endoscopic gastrostomy: a pilot study. J Clin Gastroenterol 1997;24:71-3.

22 Clarfield AM, Monette J, Bergman $\mathrm{H}$ et al. Enteral feeding in endstage dementia: a comparison of religious, ethnic, and national differences in Canada and Israel. J Gerontol A Biol Sci Med Sci 2006:61:621-7.

23 Kurien M, Leeds JS, DeLegge MH et al. Mortality among patients who receive or defer gastrostomies. Clin Gastroenterol Hepatol 2013;11:1445-50.

24 Holt DQ, McDonald JF, Murray ML et al. Clinical selection criteria can predict futile intervention in patients referred for percutaneous endoscopic gastrostomy insertion. Intern Med J 2015;45:648-52.

25 Demertzi A, Ledoux D, Bruno MA et al. Attitudes towards end of-life issues in disorders of consciousness: a European survey. J Neurol 2011;258:1058-65.

26 Leeds JS, McAlindon ME, Grant J et al. Albumin and patient age predict outcomes in patients referred for gastrostomy insertion: internal and external validation of the Sheffield Gastrostomy Score and comparison with artificial neural networks. Gastrointest Endosc 2011;74:1033-9.

27 Kurien M, Sanders DS. Improving outcomes following percutaneous endoscopic gastrostomy (PEG) - a seven-day waiting policy is essential. Clin Med 2011;11:411.

Address for correspondence: Dr Heather Parr, Royal Hallamshire Hospital, Glossop Road, Sheffield S10 2JF, UK.

Email: h.parr@nhs.net 